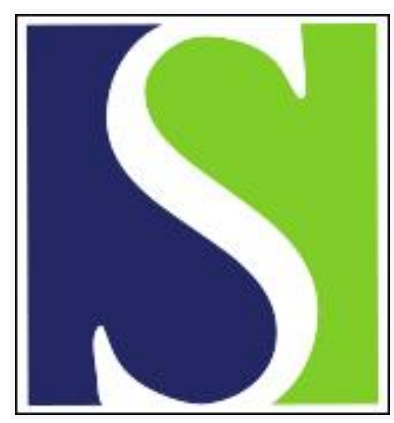

Scand J Work Environ Health 2015;41(6):511-518

https://doi.org/10.5271/sjweh.3521

Published online: 03 Sep 2015, Issue date: 01 Nov 2015

Changes in working conditions and physical health functioning among midlife and ageing employees

by Mänty M, Kouvonen A, Lallukka T, Lahti J, Lahelma E, Rahkonen $\mathrm{O}$

This study examines the effect of changes in physical and psychosocial working conditions on physical health functioning among midlife and ageing municipal employees. We found that adverse changes in physical working conditions and job control are associated with increased decline in physical health functioning over a 10-12-year follow-up, whereas favorable changes in these exposures reduce the decline.

Affiliation: Department of Public Health, University of Helsinki, PO Box 41, FIN-00014, Finland. minna.manty@helsinki.fi

Refers to the following text of the Journal: 2013;39(2):164-169

The following articles refer to this text: $2015 ; 41(6): 509-510$; 2017;43(6):587-594; 2022;48(8):662-671; 2023;49(2):95-98

Key terms: ageing; ageing employee; follow-up; midlife; physical health; physical health functioning; physical working condition; psychosocial working condition; SF-36; working condition

This article in PubMed: www.ncbi.nlm.nih.gov/pubmed/26332434

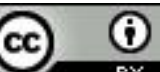




\title{
Changes in working conditions and physical health functioning among midlife and ageing employees
}

\author{
by Minna Mänty, PhD, ${ }^{1}$ Anne Kouvonen, PhD, 2, 3, 4 Tea Lallukka, PhD, ${ }^{1,5}$ Jouni Lahti, PhD, ${ }^{1}$ Eero Lahelma, \\ $P h D,{ }^{1}$ Ossi Rahkonen $P h D^{1}$
}

\begin{abstract}
Mänty M, Kouvonen A, Lallukka T, Lahti J, Lahelma E, Rahkonen 0. Changes in working conditions and physical health functioning among midlife and ageing employees. Scand J Work Environ Health. 2015;41(6):511-518. doi:10.5271/sjweh.3521
\end{abstract}

Objectives The aim this study was to examine the effect of changes in physical and psychosocial working conditions on physical health functioning among ageing municipal employees.

Methods Follow-up survey data were collected from midlife employees of the City of Helsinki, Finland, at three time points: wave 1 (2000-2002), wave 2 (2007), and wave 3 (2012). Changes in physical and psychosocial working conditions were assessed between waves 1 and 2 . Physical health functioning was measured by the physical component summary (PCS) of the Short-Form 36 questionnaire at each of the three waves. In total, 2784 respondents $(83 \%$ women) who remained employed over the follow-up were available for the analyses. Linear mixed-effect models were used to assess the associations and adjust for key covariates (age, gender, obesity, chronic diseases, and health behaviors).

Results Repeated and increased exposure to adverse physical working conditions was associated with greater decline in physical health functioning over time. In contrast, decrease in exposures reduced the decline. Of the psychosocial working conditions, changes in job demands had no effects on physical health functioning. However, decreased job control was associated with greater decline and repeated high or increased job control reduced the decline in physical health functioning over time.

Conclusions Adverse changes in physical working conditions and job control were associated with greater decline in physical health functioning over time, whereas favorable changes in these exposures reduced the decline. Preventing deterioration and promoting improvement of working conditions are likely to help maintain better physical health functioning among ageing employees.

Key terms physical working condition; psychosocial working condition; SF-36; follow-up.

Good physical functioning is vital for work ability and everyday life. Limited physical functioning, such as difficulties in mobility, is an early marker of declining health and subsequent early exit from the labor market $(1,2)$ and threatens the individual's independence and quality of life $(3,4)$. The workforce is ageing rapidly in post-industrial societies; (5) this highlights the importance of understanding factors contributing to physical functioning among ageing employees. During the past few decades, many clinical and epidemiological stud- ies have identified multiple determinants of functional decline, including various chronic diseases, and sociodemographic and lifestyle factors $(6,7)$.

In addition, previous studies have indicated that physically demanding working conditions, such as repetitive monotonous work or lifting (8-12), and psychosocially demanding working conditions, such as low job control or high job demands (13-16), are associated with poorer physical functioning among midlife and older employees. However, evidence on the health

\footnotetext{
1 Department of Public Health, University of Helsinki, Helsinki, Finland.

2 Department of Social Research, University of Helsinki, Helsinki, Finland.

3 University of Social Sciences and Humanities, Faculty in Wroclaw, Wroclaw, Poland.

4 UKCRC Centre of Excellence for Public Health (Northern Ireland), Queen's University Belfast, Belfast, UK.

5 Centre of Expertise for Health, Work Ability \& Disability Prevention Research Centre, Finnish Institute of Occupational Health, Helsinki, Finland

Correspondence to: Minna Mänty, Department of Public Health, University of Helsinki, PO Box 41, FIN-00014, Finland. [E-mail: minna manty@helsinki.fi]
} 
effects of changes in these working conditions is insufficient, especially for physical working conditions. Some previous studies have suggested that adverse changes in physical (17) and psychosocial (17-20) working conditions contribute to sickness absence $(17,18)$ and mental disorders $(19,20)$, but prior studies have not examined whether adverse or positive changes in working conditions contribute to physical functioning.

We examined the effects of changes in physical and psychosocial working conditions on physical health functioning among midlife and ageing employees during a follow-up of 10-12 years.

\section{Methods}

\section{Participants}

This study is part of the Helsinki Health Study, which examines the health and well-being of the ageing employees of the City of Helsinki, Finland. Baseline (wave 1) data were collected by postal surveys in 2000, 2001, and 2002 among employees reaching 40, 45, 50, 55, or 60 years of age in each year (21). The target population consisted of 13346 employees, of which $67 \%$ returned the baseline questionnaire $(\mathrm{N}=8960)$. The follow-up surveys were conducted among the baseline respondents in 2007 (wave 2, $\mathrm{N}=7332$, response rate 83\%) and 2012 (wave 3, $\mathrm{N}=6814$, response rate $79 \%$ ). According to the non-response analysis, the baseline and follow-up data satisfactorily represent the target population (22).

For the purposes of this study, we focused on those who remained employed during the entire follow-up $(\mathrm{N}=3280)$. This restriction was needed to have information on physical and psychosocial working conditions from two consecutive time points (wave 1 and wave 2) and due to the fact that our additional analysis showed that the changes in physical health functioning were markedly different among those who retired or left employment for other reasons between wave 2 and wave 3 (data not shown). The main reason for non-employment during the follow-up was retirement $(\mathrm{N}=2895)$. Furthermore, respondents with missing information on physical functioning at waves $1-3(\mathrm{~N}=185)$ or on any of the working conditions at wave 1 or wave $2(\mathrm{~N}=311)$ were excluded. This yielded 2784 participants.

The ethics committees of the Department of Public Health, University of Helsinki and the health authorities of the City of Helsinki, Finland, approved this study.

\section{Measurement of physical workload}

Physical working conditions were measured at waves 1 and 2 with the following six items: (i) awkward working postures, (ii) rotation of back, (iii) repetitive movements, (iv) standing, (v) walking, and (vi) heavy physical effort or lifting and carrying heavy loads (23). The participants were asked to report whether these demands were present in their work (yes/no).

Changes in the exposure to physical working conditions were measured by a four-category variable of change for each of the six exposure variables (17): (i) no exposure (no exposure at either wave 1 or 2), (ii) increased exposure (no exposure at wave 1, exposure at wave 2), (iii) decreased exposure (exposure at wave 1 , no exposure at wave 2), and (iv) repeated exposure (exposure at wave 1 and 2).

\section{Measurement of psychosocial working conditions}

The Framingham version of Karasek's Job Content Questionnaire (24) was used to measure job demands and job control at waves 1 and 2. Job demands were measured by five items inquiring about excessive work, conflicting demands, insufficient time to work, fast pace and working hard (Cronbach's alpha $\alpha=0.72$ ), and job control, which consists of decision authority and skill discretion, was measured by nine items ( $\alpha$ $=0.82$ ). Each answer was scored on a scale 1 (strongly disagree) to 4 (strongly agree). The demand and control scales were separately summed up. Job demands and job control variables were dichotomized to low and high job demands and job control, respectively, by using the median values as cut off points.

Changes in exposure to psychosocial working conditions were measured by a four-category variable as follows (17): (i) no exposure (low exposure at wave 1 and 2), (ii) increased exposure (low exposure at wave 1 , high exposure at wave 2), (iii) decreased exposure (high exposure at wave 1, low exposure at wave 2), (iv) repeated exposure (high exposure at wave 1 and 2). No exposure to high job demands and exposure to high job control are considered beneficial

\section{Measurement of physical functioning}

Physical health functioning was measured by the physical component summary (PCS) of the Short-Form 36 (SF-36) health questionnaire (25) at each of the three waves. The PCS is a continuous scale, ranging from $0-100$, with a mean of 50 [standard deviation (SD) 10] in the general US population (25). High scores indicate good physical health functioning. The SF-36 has a good construct validity and high internal consistency as well as test-retest reliability (25). As a continuous measure, SF-36 is well-suited for analyzing changes of functioning, and it captures even small changes in functioning better than commonly used dichotomous health measures. 


\section{Covariates}

Age at wave 1 included five groups: 40, 45, 50, and 55 years in 2000, 2001, and 2002. Other variables were measured at each of the three waves and were used as time-variant. Body mass index (BMI) was calculated as weight in kilograms divided by height in metres squared, using self-reports and classified into non-obese $(\leq 30 \mathrm{~kg} /$ $\left.\mathrm{m}^{2}\right)$ and obese $\left(>30 \mathrm{~kg} / \mathrm{m}^{2}\right)$. Smoking was categorized to as non-smoker, ex-smoker, and current smoker. Alcohol use was measured by binge drinking, which implied drinking $>6$ servings on a single occasion $\geq 1$ times per month. Participants were classified into two groups according to their level of self-reported leisure-time physical activity: (i) inactive [ $\leq 14$ metabolic equivalent (MET) hours/week], (ii) active ( $\geq 15$ MET hours/ week) (eg, brisk walking for 30 minutes 5 days/week = 15 MET hours/week). The main analysis used a list of self-reported medically confirmed chronic diseases that are likely to affect physical functioning (osteoporosis, osteoarthritis, rheumatoid arthritis, angina pectoris, heart attack, cerebral hemorrhage, intermittent claudication, asthma, depression, other mental illness, diabetes, and cancer). For descriptive purposes the following categories were used: 0 or $\geq 1$ diseases.

\section{Statistical analysis}

Study population characteristics are reported as percentages and mean values of SF-36 physical health functioning score (PCS) at wave 1 with $95 \%$ confidence intervals $(95 \% \mathrm{CI})$. The effect of changes in working conditions on physical functioning was analyzed in two steps. First, the adjusted cross-sectional differences in PCS score at waves 1 and 3 were calculated by changes in working conditions using linear regression analysis (table 2). In these analyses, the covariates where derived from the same time-point as PCS. To be able to evaluate the group differences in PCS before and after the changes in working conditions, we report the mean differences separately for wave 1 and wave 3 . Second, adjusted differences in the changes of PCS score from wave 1 to wave 3 were calculated by changes in working conditions using linear mixed-effect regression models (table 3 ). In these longitudinal analyses, the covariates were derived from all three waves and they were used as time-variant. To be able to have the last measurement of the outcome after the changes in working conditions had taken place (wave 1 to wave 2), the change in PCS was measured from wave 1 to wave 3. Furthermore, we did not include the information on working conditions at wave 3 in these analyses as it would have decreased the statistical power due to additional exposure categories. The results are reported as regression coefficients $(\beta)$ and their standard errors (SE). Men and women were pooled in the analyses as gender interactions were statistically non-significant. To be able to measure the effect of increase and decrease in the exposure to working conditions, the job exposure group in which the participants were at wave 1 (ie, prior to the exposure change) was used as the reference category. For example, when examining decreased exposure to a particular adverse physical working condition, one must have had such an exposure at wave 1. The SAS 9.4 Statistical Package was used for all analyses (SAS institute Inc, Cary, NC, USA).

\section{Results}

Physical health functioning at wave 1 was lower among older participants and those who had $\geq 1$ chronic diseases. In addition, obesity, smoking, binge drinking, and low physical activity were associated with poorer physical health functioning (table 1).

\section{Physical working conditions}

Exposure to physical working conditions was common with up to two thirds reporting repeated exposure to adverse physical working conditions (table 1). Physical health functioning was the lowest among those with repeated exposure to physical workloads and the highest among those with no exposure (table 1, table 2). The differences in physical functioning widened during the follow-up as the decline was more pronounced among those with repeated or increased exposure compared to those with no exposure (table 2, table 3). However, the decline was smaller among those who reported decreased exposure compared to those with repeated exposure. For example, those with repeated or increased exposure to rotation of back in their work had $2.6(\mathrm{P}<0.001)$ and 1.0 $(\mathrm{P}=0.042)$ points lower scores at wave 1 , respectively, as compared to those with no exposure after adjustment for gender and age (table 2). The decline among those with repeated or increased exposure was greater during the follow-up as compared to those with no exposure $(-3.5$ versus $-1.9, \mathrm{P}<0.001$ and -2.9 versus $-1.9, \mathrm{P}=0.024$, respectively, table 3$)$ resulting into $-4.1(\mathrm{P}<0.001)$ and $-2.0(\mathrm{P}=0.001)$ points lower physical health functioning scores, respectively, at wave 3 (table 2). In addition, those who reported decreased exposure had smaller decrease in physical health functioning score $(-1.8$ versus $-3.5, \mathrm{P}<0.001$, table 3 ) resulting into 3.0 points higher $(\mathrm{P}<0.001$, table 2$)$ score at wave 3 as compared to those who reported repetitive exposure to rotation of back. Although further adjustments for obesity and chronic diseases attenuated the associations somewhat, the general conclusions of the results did not change (table 2 and table 3; model 2). Smoking, binge drink- 
Table 1. Unadjusted percentage of participants and Short Form-36 (SF-36) physical health functioning component summary (PCS) scores at wave $1(\mathrm{~N}=2784)$. [95\% $\mathrm{Cl}=95 \%$ confidence interval.]

\begin{tabular}{|c|c|c|c|}
\hline Characteristic at wave 1 & $\%$ & Mean & $95 \% \mathrm{Cl}$ \\
\hline \multicolumn{4}{|l|}{ Gender } \\
\hline Women & 83 & 51.9 & $51.3-52.4$ \\
\hline Men & 17 & 51.8 & $50.6-51.2$ \\
\hline \multicolumn{4}{|l|}{ Age } \\
\hline 40 & 32 & 51.4 & $50.9-51.9$ \\
\hline 45 & 34 & 51.3 & $50.9-51.8$ \\
\hline 50 & 30 & 50.4 & $49.9-50.9$ \\
\hline 55 & 4 & 50.7 & $49.2-52.2$ \\
\hline \multicolumn{4}{|l|}{ Obesity } \\
\hline No & 90 & 51.4 & $51.1-51.7$ \\
\hline Yes & 10 & 48.1 & $47.2-49.0$ \\
\hline \multicolumn{4}{|c|}{ Number of chronic conditions } \\
\hline 0 & 76 & 52.0 & $51.7-52.2$ \\
\hline$\geq 1$ & 24 & 48.2 & $47.6-48.7$ \\
\hline \multicolumn{4}{|l|}{ Binge drinking } \\
\hline No & 77 & 50.9 & $50.6-51.2$ \\
\hline Yes & 23 & 51.6 & $51.1-52.1$ \\
\hline \multicolumn{4}{|l|}{ Smoking } \\
\hline No & 53 & 51.3 & $51.0-51.7$ \\
\hline Previous & 24 & 50.9 & $50.3-51.4$ \\
\hline Current & 23 & 50.6 & $50.0-51.1$ \\
\hline \multicolumn{4}{|l|}{ Physical activity } \\
\hline Inactive & 21 & 49.5 & $48.9-50.1$ \\
\hline Active & 79 & 51.5 & $51.2-51.7$ \\
\hline \multicolumn{4}{|c|}{$\begin{array}{l}\text { Change in working conditions } \\
\text { between waves } 1-2\end{array}$} \\
\hline \multicolumn{4}{|c|}{ Awkward positions } \\
\hline No exposure & 17 & 52.5 & $51.5-53.4$ \\
\hline Increased exposure & 9 & 51.9 & $50.6-53.3$ \\
\hline Decreased exposure & 14 & 51.2 & $50.2-52.2$ \\
\hline Repeated exposure & 60 & 49.2 & $48.5-49.9$ \\
\hline \multicolumn{4}{|l|}{ Rotation of back } \\
\hline No exposure & 22 & 52.1 & $51.3-52.9$ \\
\hline Increased exposure & 10 & 52.4 & $51.1-53.8$ \\
\hline Decreased exposure & 13 & 51.4 & $50.2-52.6$ \\
\hline Repeated exposure & 55 & 48.9 & $48.2-49.6$ \\
\hline \multicolumn{4}{|l|}{ Repetitive movements } \\
\hline No exposure & 19 & 51.9 & $50.9-52.9$ \\
\hline Increased exposure & 11 & 52.1 & $50.8-53.5$ \\
\hline Decreased exposure & 13 & 51.3 & $50.1-52.4$ \\
\hline Repeated exposure & 57 & 49.4 & $48.8-50.1$ \\
\hline \multicolumn{4}{|l|}{ Standing } \\
\hline No exposure & 14 & 52.0 & $50.9-53.1$ \\
\hline Increased exposure & 8 & 51.7 & $50.5-52.9$ \\
\hline Decreased exposure & 12 & 51.0 & $49.7-52.3$ \\
\hline Repeated exposure & 66 & 49.6 & $49.0-50.3$ \\
\hline \multicolumn{4}{|l|}{ Walking } \\
\hline No exposure & 8 & 52.0 & $50.6-53.4$ \\
\hline Increased exposure & 8 & 50.0 & $48.4-51.6$ \\
\hline Decreased exposure & 9 & 51.8 & $50.5-53.1$ \\
\hline Repeated exposure & 75 & 50.0 & $49.4-50.5$ \\
\hline \multicolumn{4}{|l|}{ Heavy physical effort } \\
\hline No exposure & 42 & 51.7 & $51.1-52.3$ \\
\hline Increased exposure & 9 & 51.3 & $49.9-52.7$ \\
\hline Decreased exposure & 13 & 50.5 & $48.9-52.0$ \\
\hline Repeated exposure & 36 & 48.6 & $47.7-49.4$ \\
\hline Job demands & & & \\
\hline No exposure & 39 & 51.3 & $50.5-52.0$ \\
\hline Increased exposure & 14 & 49.6 & $48.0-51.0$ \\
\hline Decreased exposure & 17 & 50.7 & $49.6-51.7$ \\
\hline Repeated exposure & 30 & 49.4 & $48.5-50.3$ \\
\hline Job control & & & \\
\hline No exposure & 31 & 49.6 & $48.8-50.4$ \\
\hline Increased exposure & 14 & 50.5 & $48.9-52.2$ \\
\hline Decreased exposure & 12 & 50.6 & $49.3-51.9$ \\
\hline Repeated exposure & 43 & 51.0 & $50.3-51.7$ \\
\hline
\end{tabular}

ing, and physical activity had only minor effects on the estimates (table 2 and table 3; model 3).

\section{Psychosocial working conditions}

Around one third of the participants reported being exposed repeatedly to adverse psychosocial working conditions (table 1). Physical health functioning was the lowest among those with repeated exposure and the highest among those with no exposure to adverse psychosocial working conditions (table 1, table 2). There were no differences in the mean change of physical functioning scores according to changes in job demands. For job control, the differences in physical functioning widened during the follow-up (table 2) as the decline was smaller among those with repeated high control compared to those with repeated low control ( -2.4 versus $-3.5, \mathrm{P}<0.001$, table 3 ) resulting into 2.4 point difference $(\mathrm{P}<0.001)$ in physical health functioning score at wave 3 (table 2). Furthermore, the decline was greater among those with decrease in job control as compared to those with job control remaining high $(-3.1$ versus $-2.4, \mathrm{P}=0.035$, table 3 ). Although further adjustments for obesity and chronic diseases attenuated the estimates somewhat, the general conclusions of the results did not change (table 2 and table 3; Model 2). Smoking, binge drinking, and physical activity had only minor effects on the estimates (table 2 and table 3; model 3).

\section{Discussion}

Our study showed that repeated and increased exposure to adverse physical working conditions was associated with greater decline in physical health functioning over time. In contrast, decrease in exposures reduced the decline. Of the psychosocial working conditions, changes in job demands had no effects on physical health functioning. However, decreased job control was associated with greater decline, whereas repeated high or increased job control reduced the decline in physical health functioning over time.

Our findings on the effects of adverse physical and psychosocial working conditions on physical health functioning confirm those from previous studies (8-16). In particular, they extend the existing research by providing novel evidence on the effects of changes in these working conditions. Such evidence is important for the prevention of loss of functioning among ageing employees and offers insights into potentially modifiable working conditions. Although the observed group differences in the means (table 2) and mean changes (table 3) of physical health functioning scores were fairly small, many of them were close to $>3$ points, which has been 
Table 2. Adjusted differences in means (B coefficients) of short form (SF) 36 physical health functioning score (PCS) before (wave 1) and after (wave 3) changes in working conditions from wave 1 to wave 2. [SE=standard error].

\begin{tabular}{|c|c|c|c|c|c|c|c|c|c|c|c|c|}
\hline & \multicolumn{4}{|c|}{ Model $1^{\text {a }}$} & \multicolumn{4}{|c|}{ Model $2^{b}$} & \multicolumn{4}{|c|}{ Model $3^{c}$} \\
\hline & \multicolumn{2}{|c|}{ wave 1} & \multicolumn{2}{|c|}{ wave 3} & \multicolumn{2}{|c|}{ wave 1} & \multicolumn{2}{|c|}{ wave 3} & \multicolumn{2}{|c|}{ wave 1} & \multicolumn{2}{|c|}{ wave 3} \\
\hline & B & SE & $B$ & SE & $B$ & SE & $\beta$ & SE & B & SE & B & SE \\
\hline \multicolumn{13}{|l|}{ Awkward positions } \\
\hline Increased exposure ${ }^{d}$ & -0.9 & 0.6 & -1.3 & 0.7 & -0.6 & 0.5 & -1.1 & 0.6 & -0.9 & 0.6 & -1.3 & $0.6^{\mathrm{e}}$ \\
\hline Repeated exposure ${ }^{d}$ & -2.7 & $0.4^{e}$ & -4.0 & $0.4 \mathrm{e}$ & -2.4 & $0.4 \mathrm{e}$ & -3.3 & $0.4^{\mathrm{e}}$ & -2.7 & $0.4 \mathrm{e}$ & -3.8 & $0.4 \mathrm{e}$ \\
\hline Decreased exposure ${ }^{f}$ & 0.9 & $0.4 \mathrm{e}$ & 2.7 & $0.5 \mathrm{e}$ & 0.8 & $0.4 \mathrm{e}$ & 2.3 & $0.4 \mathrm{e}$ & 0.9 & $0.4 \mathrm{e}$ & 2.6 & $0.5^{e}$ \\
\hline \multicolumn{13}{|l|}{ Rotation of back } \\
\hline Increased exposure & -1.0 & $0.5^{e}$ & -2.0 & $0.6^{\mathrm{e}}$ & -1.0 & 0.5 & -2.1 & $0.6^{\mathrm{e}}$ & -1.1 & $0.5^{\mathrm{e}}$ & -1.9 & $0.6^{\mathrm{e}}$ \\
\hline Repeated exposure & -2.6 & $0.3^{e}$ & -4.1 & $0.4 \mathrm{e}$ & -2.2 & $0.3 \mathrm{e}$ & -3.5 & $0.4^{\mathrm{e}}$ & -2.6 & $0.3 \mathrm{e}$ & -3.9 & $0.4 \mathrm{e}$ \\
\hline Decreased exposure & 1.3 & $0.4^{\mathrm{e}}$ & 3.0 & $0.5^{\mathrm{e}}$ & 1.2 & $0.4^{\mathrm{e}}$ & 2.4 & $0.4^{\mathrm{e}}$ & 1.3 & $0.4 \mathrm{e}$ & 2.8 & $0.5^{\mathrm{e}}$ \\
\hline \multicolumn{13}{|l|}{$\begin{array}{l}\text { Repetitive movements } \\
\text { No exposure }\end{array}$} \\
\hline Increased exposure & -0.1 & 0.5 & -1.7 & $0.6^{\mathrm{e}}$ & 0.1 & 0.5 & -1.8 & $0.6^{\mathrm{e}}$ & 0.1 & 0.5 & -1.6 & $0.6^{\mathrm{e}}$ \\
\hline Repeated exposure & -2.2 & $0.4 \mathrm{e}$ & -3.6 & $0.4 \mathrm{e}$ & -1.9 & $0.3 \mathrm{e}$ & -3.0 & $0.4 \mathrm{e}$ & -2.1 & $0.4 \mathrm{e}$ & -3.3 & $0.4 \mathrm{e}$ \\
\hline Decreased exposure & 1.4 & $0.4 \mathrm{e}$ & 2.8 & $0.5^{\mathrm{e}}$ & 1.4 & $0.4^{e}$ & 2.7 & $0.5^{\mathrm{e}}$ & 1.4 & $0.4 \mathrm{e}$ & 2.6 & $0.5^{\mathrm{e}}$ \\
\hline \multicolumn{13}{|l|}{ Standing } \\
\hline \multicolumn{13}{|l|}{ No exposure } \\
\hline Increased exposure & -0.1 & 0.6 & -2.1 & $0.7^{\mathrm{e}}$ & 0.2 & 0.6 & -1.7 & $0.7^{\mathrm{e}}$ & -0.1 & 0.6 & -1.7 & $0.7^{e}$ \\
\hline Repeated exposure & -1.2 & $0.4^{\mathrm{e}}$ & -2.1 & $0.5^{\mathrm{e}}$ & -0.8 & $0.4^{e}$ & -1.6 & $0.4^{\mathrm{e}}$ & -1.2 & $0.4^{\mathrm{e}}$ & -2.0 & $0.5^{\mathrm{e}}$ \\
\hline Decreased exposure & 0.7 & 0.4 & 1.4 & $0.5^{\mathrm{e}}$ & 0.5 & 0.4 & 0.8 & 0.5 & 0.8 & 0.4 & 1.4 & $0.5^{\mathrm{e}}$ \\
\hline \multicolumn{13}{|l|}{ Walking } \\
\hline \multicolumn{13}{|l|}{ No exposure } \\
\hline Increased exposure & -0.8 & 0.7 & -0.7 & 0.7 & -0.6 & 0.6 & -0.6 & 0.7 & -0.8 & 0.7 & -0.8 & 0.8 \\
\hline Repeated exposure & -1.4 & $0.5^{\mathrm{e}}$ & -1.9 & $0.6^{\mathrm{e}}$ & -1.1 & $0.5^{\mathrm{e}}$ & -1.3 & $0.6^{\mathrm{e}}$ & -1.4 & $0.5^{\mathrm{e}}$ & -2.0 & $0.6^{e}$ \\
\hline Decreased exposure & 0.5 & 0.5 & 1.3 & $0.6^{\mathrm{e}}$ & 0.4 & 0.5 & 0.9 & 0.5 & 0.5 & 0.5 & 1.3 & $0.6^{e}$ \\
\hline \multicolumn{13}{|l|}{$\begin{array}{l}\text { Heavy physical effort } \\
\text { No exposure }\end{array}$} \\
\hline Increased exposure & -0.3 & 0.5 & -1.7 & $0.6^{\mathrm{e}}$ & -0.1 & 0.5 & -1.1 & $0.5^{\mathrm{e}}$ & -0.2 & 0.5 & -1.6 & $0.6^{\mathrm{e}}$ \\
\hline Repeated exposure & -2.1 & $0.3^{e}$ & -3.4 & $0.4 \mathrm{e}$ & -1.7 & $0.3 \mathrm{e}$ & -2.7 & $0.3^{e}$ & -2.1 & $0.3 \mathrm{e}$ & -3.1 & $0.4 \mathrm{e}$ \\
\hline Decreased exposure & 1.2 & $0.4^{\mathrm{e}}$ & 2.3 & $0.5^{\mathrm{e}}$ & 1.2 & $0.4^{\mathrm{e}}$ & 1.9 & $0.5^{\mathrm{e}}$ & 1.3 & $0.4^{\mathrm{e}}$ & 2.2 & $0.5^{\mathrm{e}}$ \\
\hline \multicolumn{13}{|l|}{ Job demands } \\
\hline \multicolumn{13}{|l|}{ No exposure } \\
\hline Increased exposure & -0.6 & 0.4 & -1.2 & $0.5 \mathrm{e}$ & -0.7 & 0.4 & -0.9 & $0.4 \mathrm{e}$ & -0.6 & 0.4 & -1.2 & $0.5^{\mathrm{e}}$ \\
\hline Repeated exposure & -1.7 & $0.3^{e}$ & -1.8 & $0.4 \mathrm{e}$ & -1.6 & $0.3^{e}$ & -1.4 & $0.4^{\mathrm{e}}$ & -1.7 & $0.3 \mathrm{e}$ & -2.0 & $0.4 \mathrm{e}$ \\
\hline Decreased exposure & 0.5 & 0.4 & 0.8 & 0.5 & 0.4 & 0.4 & 0.7 & 0.5 & 0.6 & 0.4 & 1.0 & $0.5^{\mathrm{e}}$ \\
\hline \multicolumn{13}{|l|}{ Job control } \\
\hline No exposure & & & & & & & & & & & & \\
\hline Increased exposure & 0.1 & 0.5 & 0.9 & 0.5 & 0.1 & 0.4 & 0.6 & 0.5 & 0.1 & 0.5 & 0.7 & 0.5 \\
\hline Repeated exposure & 1.4 & $0.3^{e}$ & 2.4 & $0.4 \mathrm{e}$ & 1.2 & $0.3^{e}$ & 2.3 & $0.3^{e}$ & 1.3 & $0.3^{e}$ & 2.0 & $0.4 \mathrm{e}$ \\
\hline Decreased exposure & 0.1 & 0.4 & -0.6 & 0.5 & 0.1 & 0.4 & -0.7 & 0.5 & 0.1 & 0.4 & -0.6 & 0.5 \\
\hline
\end{tabular}

${ }^{a}$ Adjusted for gender and age.

${ }^{\mathrm{b}}$ Model $1+$ adjusted for obesity and chronic diseases.

c Model $1+$ adjusted for smoking, binge drinking, and physical activity.

${ }^{d}$ Reference group is the no exposure group.

${ }^{\text {e }}$ Significantly $(\mathrm{P}<0.05)$ different from the reference group.

${ }^{\mathrm{f}}$ Reference group is the repeated exposure group.

suggested as a clinically important difference (26). Our results are also in line with a previous study in this cohort which showed that adverse changes in working conditions were associated with an increased risk and favorable changes with a decreased risk of sickness absence (17). The correspondence between the results makes sense as functional limitations have been shown to be associated with poor health and work disability (7) as well as risk of exit from the labor market $(1,2)$.

To explore possible mechanisms that may underlie the observed associations, the age- and gender-adjusted models were further adjusted for obesity, chronic condi- tions, physical activity, smoking, and binge drinking. However, these adjustments did not change the general conclusions, indicating that the deteriorating effects of adverse working conditions on physical functioning were not totally dependent on health related factors or health behaviors. Our measures on health status and health behaviors were based on self-reports and, therefore, potentially underreported. For example, as clinically confirmed cardiovascular diseases and low muscle strength have shown strong associations with poor physical functioning (27), the known effects of heavy physical work on cardiovascular diseases (28) and muscle functioning 
Table 3. Adjusted mean change ( $B$ coefficients) of SF-36 physical health functioning score (PCS) from wave 1 to wave 3 by changes in working conditions from wave 1 to wave 2. [SE=standard error].

\begin{tabular}{|c|c|c|c|c|c|c|}
\hline & \multicolumn{2}{|c|}{ Model $1^{\mathrm{a}}$} & \multicolumn{2}{|c|}{ Model $2 \mathrm{~b}$} & \multicolumn{2}{|c|}{ Model $3 \mathrm{c}$} \\
\hline & $B$ & SE & B & SE & $\beta$ & SE \\
\hline \multicolumn{7}{|l|}{ Awkward positions } \\
\hline No exposure & -2.0 & 0.2 & -1.7 & 0.2 & -2.0 & 0.2 \\
\hline Increased exposure d & -2.5 & 0.4 & -2.3 & 0.4 & -2.5 & 0.4 \\
\hline Repeated exposure ${ }^{d}$ & -3.4 & $0.2^{e}$ & -3.0 & $0.2^{\mathrm{e}}$ & -3.4 & $0.2^{\mathrm{e}}$ \\
\hline Decreased exposure ${ }^{f}$ & -1.6 & $0.3^{e}$ & -1.2 & $0.3^{e}$ & -1.5 & $0.3^{e}$ \\
\hline \multicolumn{7}{|l|}{ Rotation of back } \\
\hline No exposure & -1.9 & 0.2 & -1.5 & 0.2 & -1.9 & 0.2 \\
\hline Increased exposure & -2.9 & $0.4^{\mathrm{e}}$ & -2.6 & $0.4^{\mathrm{e}}$ & -2.8 & $0.4^{\mathrm{e}}$ \\
\hline Repeated exposure & -3.5 & $0.2^{e}$ & -3.0 & $0.2^{\mathrm{e}}$ & -3.4 & $0.2^{\mathrm{e}}$ \\
\hline Decreased exposure & -1.8 & $0.3^{e}$ & -1.6 & $0.3^{e}$ & -1.7 & $0.3^{e}$ \\
\hline \multicolumn{7}{|l|}{ Repetitive movements } \\
\hline No exposure & -1.8 & 0.2 & -1.5 & 0.2 & -1.8 & 0.2 \\
\hline Increased exposure & -3.6 & $0.4 \mathrm{e}$ & -3.4 & $0.4^{\mathrm{e}}$ & -3.6 & $0.4^{\mathrm{e}}$ \\
\hline posure & -3.3 & $0.2^{e}$ & -2.8 & $0.2^{\mathrm{e}}$ & -3.2 & $0.2^{\mathrm{e}}$ \\
\hline Decreasec & -1.9 & $0.3^{e}$ & -1.5 & $0.3^{e}$ & -1.8 & $0.3^{e}$ \\
\hline \multicolumn{7}{|l|}{ Standing } \\
\hline No exposure & -2.0 & 0.3 & -1.6 & 3 & -1.9 & 0.3 \\
\hline d exposure & - & $0.4 \mathrm{e}$ & -3.6 & $0.4^{e}$ & -3.8 & $.4 \mathrm{e}$ \\
\hline Rep & & e & -2 & $.1^{\mathrm{e}}$ & -2 & $0.1 \mathrm{e}$ \\
\hline Decrease & -2.3 & $0.3^{e}$ & -2.0 & 0.3 & -2.3 & 0.3 \\
\hline \multicolumn{7}{|l|}{ Walking } \\
\hline No exposure & -2.4 & 0.4 & -2.1 & 0.4 & -2.4 & 0.4 \\
\hline ure & -2.4 & 0.4 & -2.1 & 0.4 & -2.3 & 0.4 \\
\hline Repea & -3.0 & 0.1 & -2.6 & 0.1 & -3 & 0.1 \\
\hline Decreased exposure & -2.2 & $0.4^{\mathrm{e}}$ & -1.9 & 0.4 & -2.1 & $0.4^{\mathrm{e}}$ \\
\hline \multicolumn{7}{|l|}{ Heavy physical effort } \\
\hline No exposure & -2.2 & 0.2 & -1.9 & 0.2 & -2.1 & 0.2 \\
\hline ed exposure & -3.7 & $0.4^{\mathrm{e}}$ & -3.4 & $0.4^{\mathrm{e}}$ & -3.6 & $0.4^{\mathrm{e}}$ \\
\hline Repez & -3.6 & $0.2^{e}$ & -3.1 & $0.2^{e}$ & -3.5 & $0.2^{\mathrm{e}}$ \\
\hline $\begin{array}{l}\text { Decreased exposure } \\
\text { Job demands }\end{array}$ & -2.4 & $0.3^{e}$ & -2.1 & $0.3^{e}$ & -2.4 & $0.3^{\mathrm{e}}$ \\
\hline No ex & -2.8 & 2 & -2.5 & 2 & -2.7 & 0.2 \\
\hline osure & -3.4 & 3 & -2 & 3 & -3.3 & 0.3 \\
\hline Repeatec & -2.9 & 0.2 & -2.4 & 0.2 & -2.8 & 0.2 \\
\hline Decreased exposure & -2.7 & 0.3 & -2.2 & 0.3 & -2.6 & 0.3 \\
\hline \multicolumn{7}{|l|}{ Job control } \\
\hline No exposure & -3.5 & 0.2 & -3.0 & 0.2 & -3.4 & 0.2 \\
\hline Increased exposure & -2.7 & $0.4^{\mathrm{e}}$ & -2.4 & 0.4 & -2.6 & $0.4^{\mathrm{e}}$ \\
\hline Repeated exposure & -2.4 & $0.2 \mathrm{e}$ & -1.9 & $0.2^{e}$ & -2.3 & $0.2^{\mathrm{e}}$ \\
\hline Decreased exposure & -3.1 & $0.3 \mathrm{e}$ & -2.7 & $0.3 \mathrm{e}$ & -3.0 & $0.3^{\mathrm{e}}$ \\
\hline \multicolumn{7}{|c|}{$\begin{array}{l}\text { a Model } 1 \text { adjusted for gender and age. } \\
\text { b Model } 2 \text { adjusted for model } 1+\text { obesity and chronic diseases. } \\
\text { c Model } 3 \text { adjusted for model } 1+\text { smoking, binge drinking and physical } \\
\text { activity. }\end{array}$} \\
\hline
\end{tabular}

(10) are likely to play a role also in our results. Although previous studies have shown strong occupational class differences in change of physical functioning (29), we did not adjust the current analyses for occupational class due to potential risk of overadjustment.

Adverse psychosocial working conditions have previously shown negative short- $(13,14)$ and long-term effects $(30,31)$ on physical functioning. Moreover, similar to the present findings, it has been shown that poor job control may have more detrimental effects on physical health functioning than high job demands (30,
32). The mechanisms that are hypothesized to explain the associations between adverse psychosocial working conditions and physical functioning in older age likely relate to biological and psychological responses to chronic stress (33). Employees with high job demands and low job control at work are more likely to suffer from the negative physiological and psychological effect of excessive strain, such as cardiovascular health problems, metabolic dysregulation, and depression (33-35). This makes those exposed to adverse working conditions more vulnerable to the ageing process, which in turn may lead to lower physical functioning later in life $(32,36)$. It has been also hypothesized that individuals with adverse working conditions are more likely to follow unhealthy behaviors, such as smoking and physical inactivity (37), which are established risk factors for lower levels of physical functioning (38). However, in our study adjusting for health behaviors had only negligible effects on the results and these possible underlying pathways need to be explored further in future studies.

Our study had several strengths. First, the prospective ascertainment of diverse physical and psychosocial working conditions allowed us to measure changes in working conditions. Second, we used the validated and widely used SF-36 physical functioning component score to ascertain physical functioning during the prospective follow-up, allowing us to evaluate changes also in our outcome measure. Third, we used a large and well-characterized occupational cohort including hundreds of occupational titles.

The limitations of the study also need to be acknowledged. Some characteristics of our data limit the generalizability of the results. The participants were middleaged municipal sector employees with the majority being women. However, even if the sample is female dominated, the associations did not differ significantly between women and men, and the gender distribution reflects that of the employees of City of Helsinki and largely the Finnish municipal sector in general. Furthermore, as we had to restrict our analyses to those who remained employed during the 10-12 year followup, the data may be affected by the "healthy worker effect". Participants excluded due to exit from the labor market or missing information tended to have slightly poorer health and physical functioning at baseline as compared to those who were included in the analyses (data not shown). Further studies are needed to investigate how exposure to adverse working conditions over adult working life affects physical functioning among retired employees. Another limitation is that most of the information used is based on self-reported data and the possibility for under- or over-reporting cannot be ruled out. Furthermore, the study would have benefitted from more frequent follow-ups to better detect changes in working conditions and their effects on physical func- 
tioning. During the 5-7 year gap between the waves, there might have been some changes that remained unmeasured. Shorter time lags would be preferable. For example, in relation to mental health outcomes, the strongest relationships between psychosocial working conditions and mental health have been found using only 1- to 2-year time lags (39). In addition, further studies with more specific measures of working conditions are needed to confirm the results of this study. The measures of physical exposures were based solely on the presence of the demands in work, whereas frequency and duration were not considered. We are also likely to have missed some of the changes in psychosocial working conditions as we used median as a cut-off point for change in job demands and control. These limitations may have caused some underestimation in the observed associations. Furthermore, the interaction between job demands and control (ie, job strain) need to be addressed in future studies.

In conclusion, the present findings showed that adverse changes in several physical working conditions and job control were associated with greater decline in physical health functioning over time, whereas favorable changes in exposures reduced the decline. Preventing deterioration and promoting improvement of working conditions are likely to help maintain better physical health functioning among ageing employees.

\section{References}

1. Rice NE, Lang IA, Henley W, Melzer D. Common health predictors of early retirement: findings from the English Longitudinal Study of Ageing. Age Ageing. 2011;40:54-61. http://dx.doi.org/10.1093/ageing/afq153.

2. Stenholm S, Westerlund H, Head J, Hyde M, Kawachi I, Pentti J, et al. Comorbidity and Functional Trajectories From Midlife to Old Age: The Health and Retirement Study. J Gerontol A Biol Sci Med Sci. 2015;70(3):332-8. http://dx.doi. org/10.1093/gerona/glu113.

3. Cooper R, Kuh D, Cooper C, Gale CR, Lawlor DA, Matthews $\mathrm{F}$, et al. Objective measures of physical capability and subsequent health: a systematic review. Age Ageing. 2011 Jan;40:14-23. http://dx.doi.org/10.1093/ageing/afq117.

4. Cooper R, Kuh D, Hardy R. Objectively measured physical capability levels and mortality: systematic review and meta-analysis. BMJ. 2010 Sep 9;341:c4467. http://dx.doi. org/10.1136/bmj.c4467.

5. Christensen K, Doblhammer G, Rau R, Vaupel JW. Ageing populations: the challenges ahead. Lancet. 2009;374:1196208. http://dx.doi.org/10.1016/S0140-6736(09)61460-4.

6. Brown CJ, Flood KL. Mobility limitation in the older patient: a clinical review. JAMA. 310:1168-77. http://dx.doi. org/10.1001/jama.2013.276566.

7. Stuck AE, Walthert JM, Nikolaus T, Bu CJ, Hohmann C, Beck JC. Risk factors for functional status decline in communityliving elderly people : a systematic literature review. Soc Sci Med. 1999;48:445-69. http://dx.doi.org/10.1016/S0277-
9536(98)00370-0.

8. Geuskens GA, Burdorf A, Barendregt PJ, Hazes JM. A high physical workload and high job demands hamper the good prognosis in physical functioning in persons with early inflammatory joint conditions. Rheumatology. 2011;50:78998. http://dx.doi.org/10.1093/rheumatology/keq359.

9. Leino-Arjas P, Solovieva S, Riihimäki H, Kirjonen J, Telama R. Leisure time physical activity and strenuousness of work as predictors of physical functioning: a 28 year follow up of a cohort of industrial employees. Occup Environ Med. 2004;61:1032-8. http://dx.doi.org/10.1136/ oem.2003.012054.

10. Savinainen M, Nygård C-H, Ilmarinen J. A 16-year follow-up study of physical capacity in relation to perceived workload among ageing employees. Ergonomics. 2004;47:1087-102. http://dx.doi.org/10.1080/00140130410001686357.

11. Mänty M, Møller A, Nilsson C, Lund R, Christensen U, Avlund K. Association of physical workload and leisure time physical activity with incident mobility limitations: a followup study. Occup Environ Med 2014;71:543-8. http://dx.doi. org/10.1136/oemed-2013-101883.

12. Hinrichs $T$, von Bonsdorff MB, Törmäkangas $T$, von Bonsdorff ME, Kulmala J, Seitsamo J, et al. Inverse effects of midlife occupational and leisure time physical activity on mobility limitation in old age--a 28-year prospective follow-up study. JAGS 2014;62:812-20. http://dx.doi.org/10.1111/jgs.12793.

13. Cheng Y, Kawachi I, Coakley EH, Schwartz J, Colditz G. Association between psychosocial work characteristics and health functioning in American women: prospective study. BMJ 2000;320:1432-6. http://dx.doi.org/10.1136/ bmj.320.7247.1432.

14. Stansfeld SA, Bosma H, Hemingway H, Marmot MG. Psychosocial Work Characteristics and Social Support as Predictors of SF-36 Health Functioning: The Whitehall II Study. Psychosom Med. 1998;60:247-55. http://dx.doi. org/10.1097/00006842-199805000-00004.

15. Von Bonsdorff MB, Seitsamo J, von Bonsdorff ME, Ilmarinen J, Nygård C-H, Rantanen T. Job strain among blue-collar and white-collar employees as a determinant of total mortality: a 28year population-based follow-up. BMJ Open. 2012;2:e000860. http://dx.doi.org/10.1136/bmjopen-2012-000860.

16. Hansen AM, Darsø L, Mänty M, Nilsson C, Christensen $\mathrm{U}$, Lund R, et al. Psychosocial factors at work and the development of mobility limitations among adults in Denmark. Scand J Public Health. 2014;42:417-24. http://dx.doi. org/10.1177/1403494814527526.

17. Saastamoinen P, Laaksonen M, Lahelma E, Lallukka T, Pietiläinen O, Rahkonen O. Changes in working conditions and subsequent sickness absence. Scand J Work Env Health. 2014;40:82-8. http://dx.doi.org/10.5271/sjweh.3379.

18. Head J, Kivimäki M, Martikainen P, Vahtera J, Ferrie JE, Marmot MG. Influence of change in psychosocial work characteristics on sickness absence: The Whitehall II Study. J. Epidemiol Community Health. 2006;60:55-61. http://dx.doi. org/10.1136/jech.2005.038752. 
19. Wang J, Schmitz N, Dewa C, Stansfeld S. Changes in perceived job strain and the risk of major depression: results from a population-based longitudinal study. Am J Epidemiol. 2009;169:1085-91. http://dx.doi.org/10.1093/aje/kwp037.

20. Stansfeld SA, Fuhrer R, Shipley MJ, Marmot MG. Work characteristics predict psychiatric disorder: prospective results from the Whitehall II Study. Occup Environ Med. 1999;56:302-7. http://dx.doi.org/10.1136/oem.56.5.302.

21. Lahelma E, Aittomäki A, Laaksonen M, Lallukka T, Martikainen P, Piha K, et al. Cohort Profile: The Helsinki Health Study. Int J Epidemiol 2012;42:722-30. http://dx.doi. org/10.1093/ije/dys039.

22. Laaksonen M, Aittomäki A, Lallukka T, Rahkonen $\mathrm{O}$, Saastamoinen P, Silventoinen K, et al. Register-based study among employees showed small nonparticipation bias in health surveys and check-ups. J Clin Epidemiol. 2008;61:9006. http://dx.doi.org/10.1016/j.jclinepi.2007.09.010.

23. Laaksonen M, Pitkäniemi J, Rahkonen O, Lahelma E. Work arrangements, physical working conditions, and psychosocial working conditions as risk factors for sickness absence: Bayesian analysis of prospective data. Ann Epidemiol. 2010;20:332-8. http://dx.doi.org/10.1016/j. annepidem.2010.02.004.

24. Karasek R. Job demands, job decision latitude, and mental strain: implications for job redesign. Adm Sci Quartely. 1979;24:285-308. http://dx.doi.org/10.2307/2392498.

25. Ware JE, Kosinski M, Keller SD. SF-36 Physical and Mental Component Summary Measures: A User's Manual. Boston MA: The Health Institute, New England Medical Center; 1994.

26. Samsa G, Edelman D, Rothman M, Williams G, Lipscomb J, Matchar D. Determining clinically important differences in health status measures: a general approach with illustration to the Health Utilities Index Mark II. Pharmacoeconomics. 1999;15:141-55. http://dx.doi.org/10.2165/00019053199915020-00003.

27. Hicks GE, Shardell M, Alley DE, Miller RR, Bandinelli S, Guralnik J, et al. Absolute strength and loss of strength as predictors of mobility decline in older adults: The InCHIANTI study. J Gerontol A Biol Sci Med Sci. 2012;67:66-73. http:// dx.doi.org/10.1093/gerona/glr055.

28. Petersen CB, Eriksen L, Tolstrup JS, Søgaard K, Grønbæk M, Holtermann A. Occupational heavy lifting and risk of ischemic heart disease and all-cause mortality. BMC Public Health. 2012;12:1070. http://dx.doi.org/10.1186/1471-2458-121070 .

29. Pietiläinen O, Laaksonen $\mathrm{M}$, Pitkäniemi J, Rahkonen O, Lahelma E. Changes of occupational class differences in physical functioning: a panel study among employees (20002007). J Epidemiol Community Health. 2012;66:265-70. http://dx.doi.org/10.1136/jech.2010.110270.
30. Wahrendorf M, Sembajwe G, Zins M, Berkman L, Goldberg $\mathrm{M}$, Siegrist J. Long-term effects of psychosocial work stress in midlife on health functioning after labor market exit - Results from the GAZEL study. J Gerontol B Psychol Sci Soc Sci. 2012;67:471-80. http://dx.doi.org/10.1093/geronb/gbs045.

31. Kulmala J, von Bonsdorff MB, Stenholm S, Törmäkangas $\mathrm{T}$, von Bonsdorff $\mathrm{ME}$, Nygård $\mathrm{C}-\mathrm{H}$, et al. Perceived stress symptoms in midlife predict disability in old age: a 28 -year prospective cohort study. J Gerontol A Biol Sci Med Sci. 2013;68:984-91. http://dx.doi.org/10.1093/gerona/gls339.

32. Von Bonsdorff MB, Cooper R, Kuh D. Job demand and control in mid-life and physical and mental functioning in early old age: do childhood factors explain these associations in a British birth cohort? BMJ Open. 2014;4:e05578. http://dx.doi. org/10.1136/bmjopen-2014-005578.

33. McEwen BS. Stress, Adaptation, and Disease. Ann NYAcad Sci. 1998;840:33-4. http://dx.doi.org/10.1111/j.1749-6632.1998. tb09546.x.

34. Rugulies R, Bültmann U, Aust B, Burr H. Psychosocial work environment and incidence of severe depressive symptoms: Prospective findings from a 5-year follow-up of the Danish work environment cohort study. Am J Epidemiol. 2006;163:877-87. http://dx.doi.org/10.1093/aje/kwj119.

35. Kivimäki M, Nyberg ST, Batty GD, Fransson EI, Heikkilä K, Alfredsson L, et al. Job strain as a risk factor for coronary heart disease: A collaborative meta-analysis of individual participant data. Lancet. 2012;380:1491-7. http://dx.doi.org/10.1016/ S0140-6736(12)60994-5.

36. Karlamangla AS, Singer BH, McEwen BS, Rowe JW, Seeman TE. Allostatic load as a predictor of functional decline: MacArthur studies of successful aging. J Clin Epidemiol. 2002;55:696-710. http://dx.doi.org/10.1016/ S0895-4356(02)00399-2.

37. Heikkilä K, Fransson E, Nyberg S, Zins M, Westerlund H, Westerholm P, et al. Job strain and health-related lifestyle: findings from an individual-participant meta-analysis of 118,000 working adults. Am J Public Health. 2013;103:2090 7. http://dx.doi.org/10.2105/AJPH.2012.301090.

38. Cooper R, Mishra GD, Kuh D. Physical activity across adulthood and physical performance in midlife: findings from a British birth cohort. Am J Prev Med. 2011;41:376-84. http:// dx.doi.org/10.1016/j.amepre.2011.06.035.

39. Smith PM, Bielecky A. The impact of changes in job strain and its components on the risk of depression. Am J Publich Health. 2012;102:352-8. http://dx.doi.org/10.2105/ AJPH.2011.300376.

Received for publication: 20 April 2015 